\title{
Estratégias para aumento da adesão às intervenções para perda de peso
}

- Paleo, vegetariana, cetogênica, mediterrânea, low carb ou sem glúten? Diferentes dietas podem ser adotadas, com sucesso, visando o emagrecimento. Estudos mostram que o sucesso da estratégia adotada depende de um fator: adesão em longo prazo;

- O insucesso no tratamento: é comum que após a dieta de emagrecimento haja novamente ganho de todo o peso perdido em até 5 anos;

- Comer é um ato complexo: muitos fatores influenciam o consumo de alimentos, como aspectos fisiológicos e patológicos, fase da vida, renda, orientação religiosa, valores pessoais e familiares, influências (propagandas, amigos, colegas de trabalho e escola), sensação de fome e saciedade;

- Manutenção de um estilo de vida saudável: para que sejam sustentáveis as escolhas devem estar atreladas à identidade da pessoa;

- O nutricionista como motivador: diferentes teorias podem dar suporte às estratégias inovadoras propostas pelo nutricionista para aumentar a motivação de sua clientela e a adesão ao tratamento;

- Principais teorias para mudança de comportamento em prol da vitalidade positiva: (1) teorias de aprendizagem; (2) processamento de informações; (3) modelo transteórico de mudança de comportamento; (4) condicionamento operante; (5) teoria do comportamento planejado e da ação planejada; (6) processamento da informação; (7) aprendizagem social; (8) teoria da comparação social; (9) proteção da motivação; (10) modelo de crenças em saúde; (11) teoria sóciocognitiva; (12) teoria da aprendizagem significativa;

- Prática advinda da teoria: conhecendo as teorias o nutricionista poderá propor mudanças no ambiente, estratégias para aumento da autoeficácia (pequenos e poucos objetivos, início de forma simples, modelamento, persuasão verbal, sistema de apoio, reforço, gatilhos, controle de estímulos), automonitoramento, compartilhamento de metas e treinamento de habilidades.

\section{Referências bibliográficas}

1. FITZGIBBON, M.; GANS, K.; EVANS, D. et al. Communicating Healthy Eating: Lessons Learned and Future Directions. J Nutr Educ Behav; 39(2):S63-S71, 2007.

2. GIBSON, A.A.; SAINSBURY, A. Strategies to improve adherence to dietary weight loss interventions in research and real-world settings. Behav. Sci; 7(3):44-55, 2017.

3. MIDDLETON, K.R.; ANTON, S.D.; PERRI, M.G. Long-term adherence to health behavior change. Am J Lifestyle Med; 7(6):395-404, 2013.

4. TORRES, A.A.L.; GUIMARÃES, N.G. Adesão ao tratamento dietético em pacientes portadores de Diabetes Mellitus tipo 2 atendidos no ambulatório de nutrição do Hospital Regional da Asa Norte. Nutrição Profissional; 10, 47-53, 2006.

5. WILSON, B.J. Designing Media Messages About Health and Nutrition: What Strategies Are Most Effective? J Nutr Educ Behav; 39(2):S13-S19, 2007. 